\title{
Operative Management of a Sacral Gunshot Injury via Minimally Invasive Techniques and Instrumentation
}

\author{
Francis Hao-Tso Shen ${ }^{1}$, Dino Samartzis ${ }^{2}$ \\ ${ }^{1}$ Department of Orthopaedic Surgery, University of Virginia, Charlottesville, VA, USA \\ ${ }^{2}$ Department of Orthopaedics and Traumatology, University of Hong Kong, Hong Kong, SAR China
}

Gunshot wounds to the spine account for $13 \%$ to $17 \%$ of all gunshot injuries and occur predominantly in the thoracic region. Minimally invasive spine surgery procedures implementing serial muscle dilation and the use of a tubular retracting system with a working channel minimize soft tissue trauma, facilitate less bony and soft tissue resection, decrease blood loss, minimize scarring and improve cosmesis, decrease hospitalization, and reduce postoperative pain and narcotic usage in comparison to more open, traditional approaches. Although minimally invasive spine surgery techniques and instrumentation have gained considerable attention, their application in the management of gunshot injuries to the sacrum has not been reported. The following is a brief case report of a 21-year-old male who sustained a gunshot injury to the sacrum who was managed operatively via minimally invasive spine surgery techniques and instrumentation.

Keywords: Gunshot wound; Trauma; Sacral; Spine; Minimally invasive; Surgery

\section{Introduction}

Gunshot wounds to the spine account for $13 \%$ to $17 \%$ of all gunshot injuries and occur predominantly in the thoracic region, while gunshot injuries to the sacrum are uncommon [1-3].

Although minimally invasive spine surgery techniques and instrumentation have gained considerable attention [49], their application in the management of gunshot injuries to the sacrum has not been reported, to the authors' knowledge, in the literature. The following is a brief case report of a young male who sustained a gunshot injury to the sacrum who was managed operatively via minimally invasive spine surgery techniques and instrumentation.

\section{Case Report}

The patient was a 21-year-old male who sustained multiple gunshot injuries to his lumbosacral region. The patient's initial history and examination revealed three posterior entry wounds in the lumbar spine without exit wounds, full motor strength in bilateral lower extremity, normal sensory examination of bilateral lower extremity, and symmetrical reflexes. Plain radiographic imaging demonstrated multiple projectiles in the soft tissue of the lumbosacral region with one projectile lodged within the anterior body of S2 (Fig. 1A, B).

The patient was admitted, evaluated and assessed by the trauma surgery team for local wound care, oral antibiotics and routine outpatient follow-up. He was subsequently

Received Dec 20, 2010; Revised Aug 4, 2012; Accepted Aug 20, 2012

Corresponding author: Dino Samartzis

Department of Orthopaedics and Traumatology, University of Hong Kong,

Professorial Block, 5th Floor, 102 Pokfulam Road, Pokfulam, Hong Kong, SAR China

Tel: +852-2255-4813, Fax: +852-2817-4392, E-mail: dsamartzis@msn.com 
discharged 3 days after admission. The patient returned to the Emergency Department at the University of Virginia 48 hours after discharge with complaint of erectile dysfunction and now a five-day history of constipation. The orthopaedic spine surgery service was consulted due to the concern of evolving neurologic symptoms. Upon evaluation by the spine service, the examination revealed subtle findings consistent with a S2-S4 nerve root dysfunction. This included perianal numbness, present but weak rectal tone, and weak volitional contraction. The bulbocavernous reflex was intact.

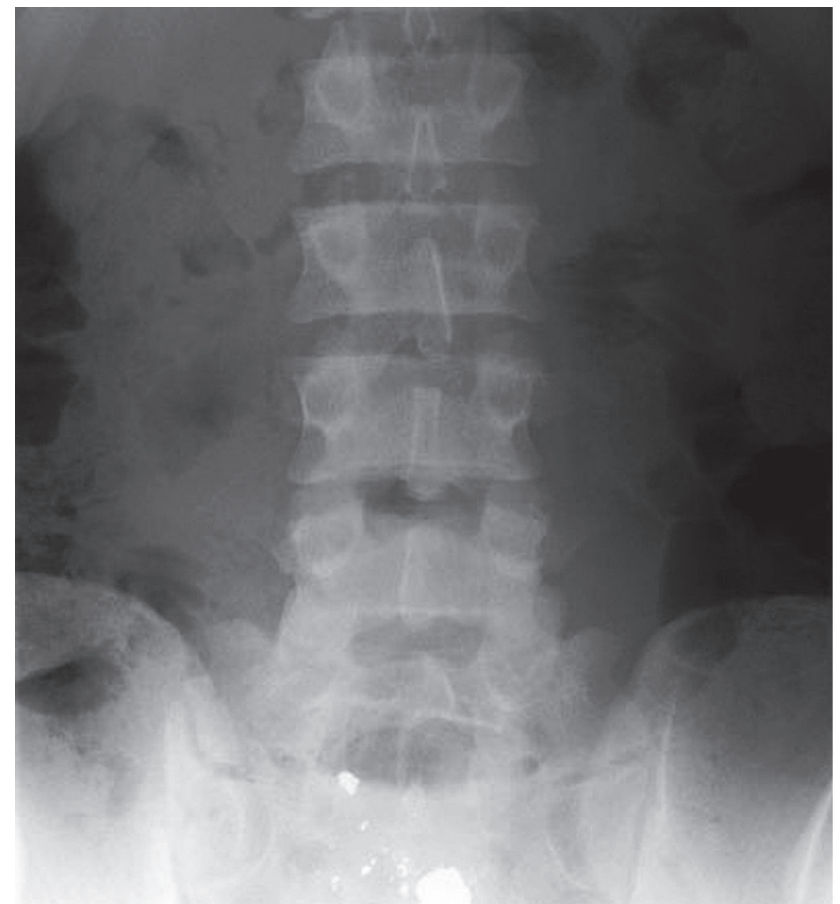

(A)
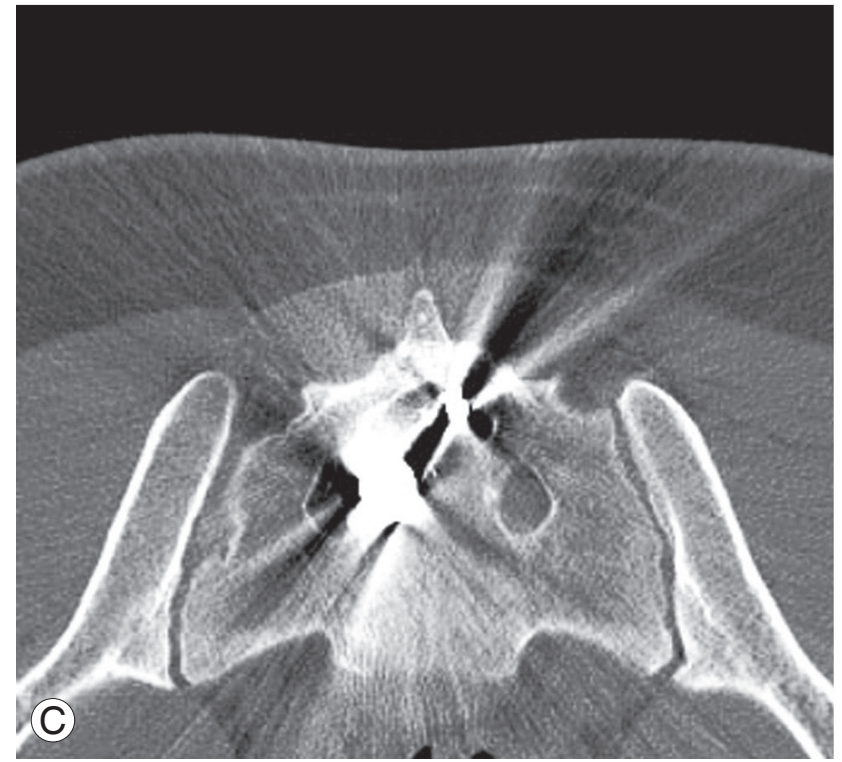

\section{(D)}

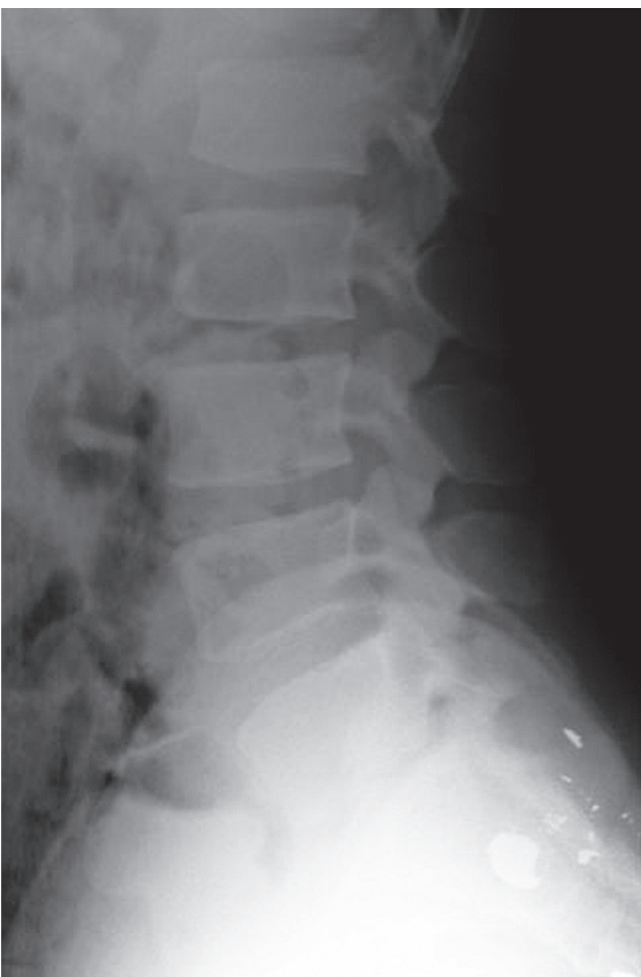

(B)

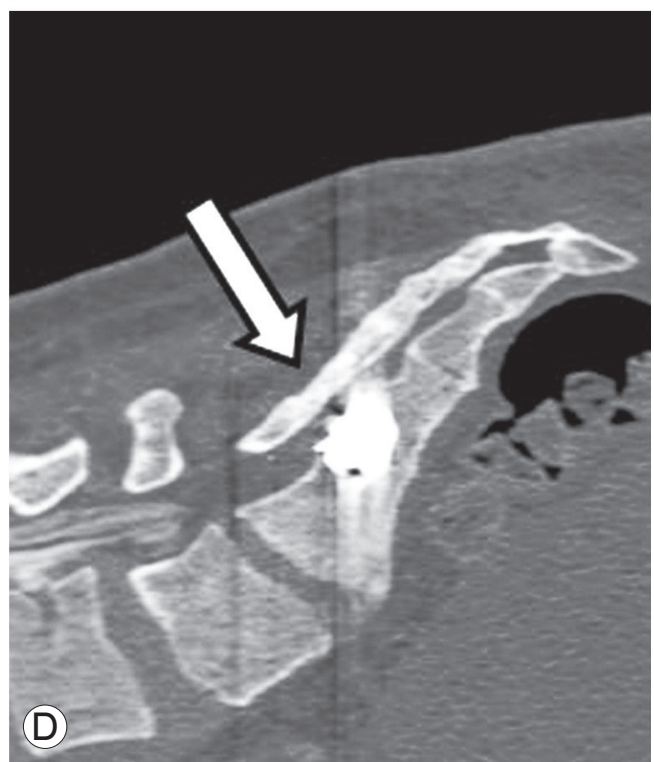

Fig. 1. Preoperative imaging. (A) Anteroposterior and (B) lateral plain radiographs illustrating the lumbosacral and sacral location of the bullet fragments secondary to a gunshot injury. (C) Axial and (D) sagittal computed tomography imaging noting the anterior right-sided location of the bullet fragment at the level of S2 (arrow). 
There was no subjective or objective motor weakness in either extremity and reflexes were symmetric.

Computed tomography (CT) scans confirmed a right-sided entry wound with an oblique trajectory through the right S2 lamina traversing the spinal canal and lodging within the anterior aspect of the S2 sacral body (Fig. 1C, D). There were no associated injuries to the vasculature, solid or hollow viscera of the abdomen or pelvis, or evidence of a hematoma or other mass effect within the spinal canal. Based on these findings, there was concern that direct nerve root injury may have occurred, or to a lesser degree, a cauda equina syndrome from an external compressive lesion. Surgical intervention was performed in the attempt to re-establish function, decompress the neural structures, and remove the projectile and any associated fragments.

General endotracheal anesthesia was administered, and routine preoperative antibiotics consisting of $1 \mathrm{~g}$ of Cefazolin were administered. The two cephalad bullet wounds were lodged within the soft tissue. These underwent local wound management with irrigation and debridement and left in place. Attention was then directed to the third and most caudal projectile (Fig. 2A). The projectile was carefully correlated with the intraoperative fluoroscopy to determine the location of the ideal skin incision, (Fig. 2B) which was
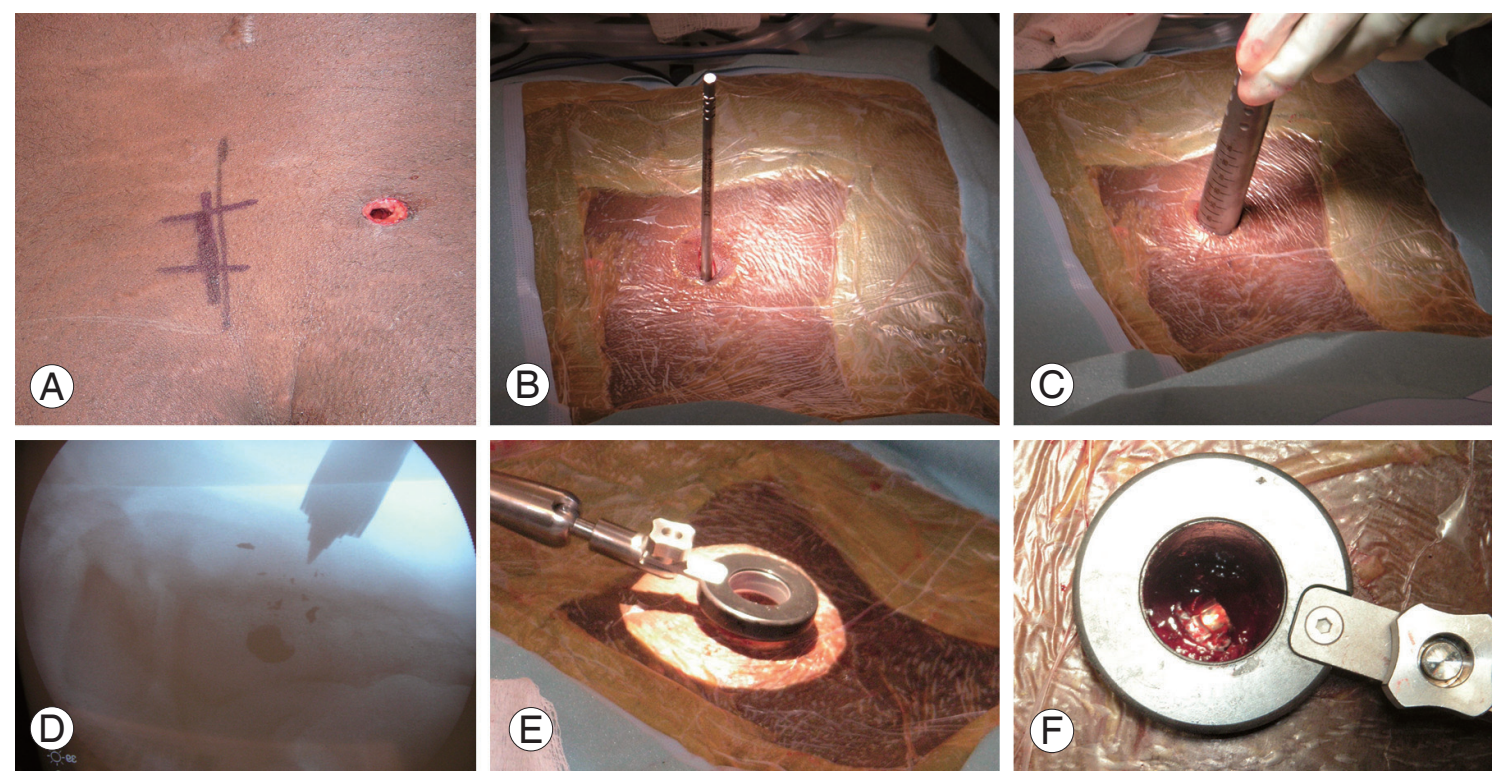

Fig. 2. Intraoperative minimally invasive approach. (A) Demonstration of the right-sided sacral location of the gunshot wound. (B, C) Application of serial muscle dilators at the site of the sacral gunshot wound. (D) Intraoperative lateral fluoroscopic image of application of muscle dilators to the sacrum. (E, F) Application of the tubular retractor and secured working channel (note the visualization of the projectile in Fig. 2F).
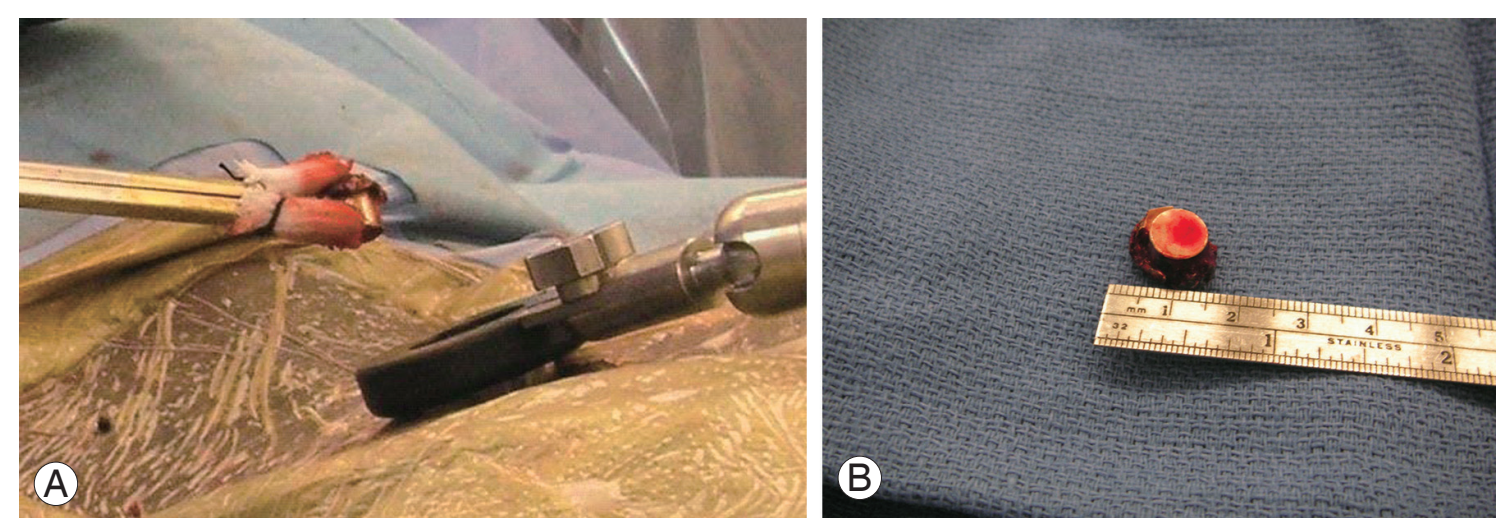

Fig. 3. (A) Intraoperative removal of bullet fragment with a shodded pituitary rongeur through the working channel. (B) Intraoperative illustration of the size of the removed bullet fragment. 
sequentially widened with larger dilators (Fig. 2C, D) (Depuy Spine, Raynham, MA, USA) at the level of the projectile (Fig. 2E, F).

A microscope was then brought into the surgical field. A decompressive laminectomy was performed at S1-S3 bilaterally. The right sacral nerve root was transected with free proximal and distal ends. Left sacral nerve roots appeared intact, but injured due to the high-energy injury of the projectile. Several bone fragments and bullet fragments within the canal were removed. The bullet projectile was found in the anterior sacrum and carefully extracted with a shodded pituitary rongeur through the working channel (Fig. 3).

Due to the muscle sparring surgical approach, there was nominal blood loss during surgical access. The estimated blood loss was under $25 \mathrm{~mL}$. No drains were required and the incision was closed with a simple running fascial stitch and interrupted nylon skin suture. The final working portal was $21 \mathrm{~mm}$ in length. No intraoperative complications were noted.

At 1-month follow-up, the patient had regained perianal sensation and partial return of bowel function as well as continence; however, he did require the occasional use of stool softners for regularity. He never required digital disimpaction. Furthermore, he regained the ability to obtain an erection, however ejaculation remained somewhat problematic. The gunshot wound healed without incidence. Motor examination of his lower extremities remains full with improvement of the heel numbness of the left lateral heel. CT imaging noted complete removal of the gunshot bullet with no associated complications (Fig. 4). Phone conversations with the patient and family at 10 months have noted an improvement only in bowel function. The remaining sexual dysfunction and sensation have plateaued.

\section{Discussion}

Sacral gunshot injuries are uncommon and have been sporadically reported in the literature [10-14]. In these cases, the history, exam, and imaging should focus on 1) evidence of evolving neurologic symptoms, 2) actual or impending mechanical instability, 3) type of gun/projectile involved, 4) associated abdominal and pelvic structures injured, and 5) final "resting place" of the projectile of interest.

Denis et al. [15] categorized the bony sacrum into three zones in the coronal plane based on their location to the sacral foramina. Our patient exhibited a Zone III injury where the region of the central sacral canal was injured and according to Denis et al. [15] it is the most infrequent classification type. Such injuries are highly associated with loss of sphincter function and the risk of neurologic injury is greatest. Management of such injuries has been noted to be problematic.

In the absence of an evolving spinal lesion, the decision to proceed with surgical removal of a projectile in the upper thoracic and cervical spine is unclear $[1,16,17]$. There is evidence to support the decision to pursue removal of projectiles that occur in the lumbosacral region, which may be due to the fact that below L1 the neurologic elements remain peripheral nerves and are more resilient to recovery after decompression. The thoracolumbar region (T11-L1) is even more controversial. While the conus medullaris remains similar to the spinal cord in ability to recover after an insult, the anatomic fact that the spinal cord is tapering in size and there is more space available for the conus medul-

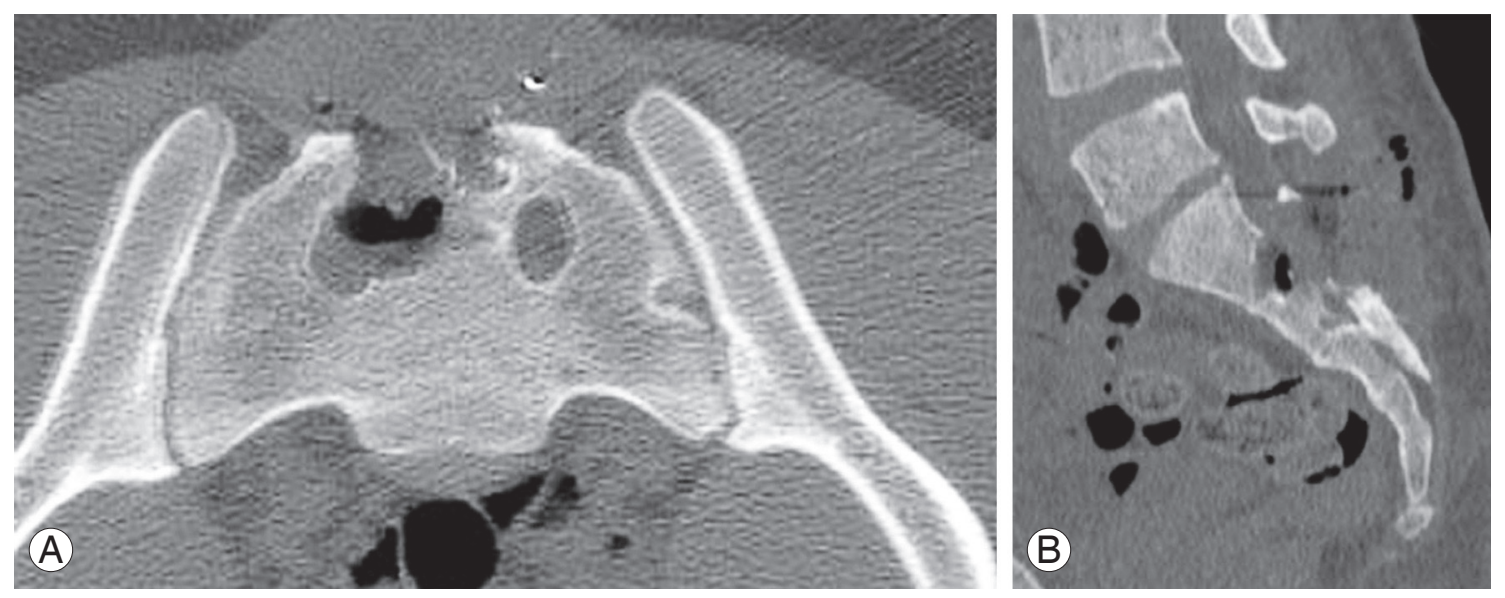

Fig. 4. One-month postoperative (A) axial and (B) sagittal computed tomography images illustrating the sacral defect following the surgical removal of bone and bullet fragments. 
laris than at levels more cephalad; and although speculative, this may account for the recovery seen at these levels after projectile extraction. Transverse injuries affecting the $\mathrm{S} 2$ and S3 nerve roots are more highly associated with bowel and bladder dysfunction than more adjacently affected nerve roots. However, with unilateral nerve injury and especially with preservation of the S2 nerve root, bowel and bladder function may be maintained $[18,19]$. Furthermore, sexual function may also be preserved with an at least one intact S3 nerve root $[20,21]$.

In patients that exhibit evidence of spinal cord injury secondary to a gunshot injury the use of high-dose steroids either as dexamethasone or methylprednisolone has not been shown to improve neurologic recovery, and in fact, may increase the rate of wound infections and gastrointestinal hemorrhages [22,23]. As a result, we do not advocate the use of high-dose steroids on a routine basis for gunshot injuries to the spine at our institution.

The use of minimally invasive instrumentation was initially reported by Foley and Smith [24] in 1997 for the operative treatment of a lumbar disc herniation, but have subsequently been applied to the management of herniated discs at all levels of the spine [6,7,25-27], interbody fusions $[4,8,28]$, intradural tumors [29], tethered cord syndrome [30], spinal stenosis [5,31], and fractures [32]. Basic science studies have noted a decrease is surgical tissue stress response utilizing such minimally invasive techniques and instrumentation in comparison to more traditional, open procedures where the risk of iatrogenic-induced tissue morbidity is increased. Furthermore, clinical studies have noted a decrease in blood loss, tissue trauma, hospitalization, and postoperative narcotic usage that translate into a quicker return to daily activities associated with such minimally invasive tactics $[28,33-$ 37].

A thorough clinical and radiographic examination is essential to determine the extent of a sacral gunshot injury and to determine the appropriateness of surgical intervention. If surgical intervention is considered, depending on the indications and goals to be achieved, the use of muscle dilators, a tubular retractor system, and application of minimally invasive surgical techniques may prove to be a very effective alternative than more open, traditional approaches for the operative treatment of selective gunshot injuries to the sacrum.

\section{Conflict of interest}

No potential conflict of interest relevant to this article was reported.

\section{References}

1. Aryan HE, Amar AP, Ozgur BM, Levy ML. Gunshot wounds to the spine in adolescents. Neurosurgery 2005;57:748-52.

2. Farmer JC, Vaccaro AR, Balderston RA, Albert TJ, Cotler J. The changing nature of admissions to a spinal cord injury center: violence on the rise. J Spinal Disord 1998;11:400-3.

3. Kupcha PC, An HS, Cotler JM. Gunshot wounds to the cervical spine. Spine 1990;15:1058-63.

4. Anderson DG, Samartzis D, Shen FH, Tannoury C. Percutaneous instrumentation of the thoracic and lumbar spine. Orthop Clin North Am 2007;38:401-8.

5. Perez-Cruet MJ, Wang MY, Samartzis D. Microendoscopic cervical laminoplasty and laminectomy. In: Kim DH, Fessler RG, Regan JJ, editors. Endoscopic spine surgery and instrumentation. New York: Thieme; 2005. p.74-87.

6. Samartzis D, Shen FH, Perez-Cruet MJ, Anderson DG. Minimally invasive spine surgery: a historical perspective. Orthop Clin North Am 2007;38:305-26.

7. Sheikh H, Samartzis D, Perez-Cruet MJ. Techniques for the operative management of thoracic disc herniation: minimally invasive thoracic microdiscectomy. Orthop Clin North Am 2007;38:351-61.

8. Shen FH, Samartzis D, Khanna AJ, Anderson DG. Minimally invasive techniques for lumbar interbody fusions. Orthop Clin North Am 2007;38:373-86.

9. Singh K, Samartzis D, Vaccaro AR, Andersson GB, An HS, Heller JG. Current concepts in the management of metastatic spinal disease. The role of minimally-invasive approaches. J Bone Joint Surg Br 2006;88:434-42.

10. Christy JP. Complications of combat casualties with combined injuries of bone and bowel: personal experience with nineteen patients. Surgery 1972;71:270-4.

11. Dunne JR, Bochicchio GV, Scalea TM. A novel approach to the treatment of gunshot injuries to the sacrum. Am Surg 2003;69:91-4.

12. Werner T, Gross AJ, Ringert RH. Erectile dysfunction caused by sacral gun-shot injury. Scand J Urol Nephrol 1999;33:69-70. 
13. Six E, Alexander E Jr, Kelly DL Jr, Davis CH Jr, McWhorter JM. Gunshot wounds to the spinal cord. South Med J 1979;72:699-702.

14. Vorob’ev GI, Protsenko VM, Salamov KN, Blagodarnyi LA, Poletov NN. Gunshot injury of the sacrum and rectum. Khirurgiia (Mosk) 1994:50-1.

15. Denis F, Davis S, Comfort T. Sacral fractures: an important problem. Retrospective analysis of 236 cases. Clin Orthop Relat Res 1988;227:67-81.

16. Klein Y, Cohn SM, Soffer D, Lynn M, Shaw CM, Hasharoni A. Spine injuries are common among asymptomatic patients after gunshot wounds. J Trauma 2005;58:8336.

17. Medzon R, Rothenhaus T, Bono CM, Grindlinger G, Rathlev NK. Stability of cervical spine fractures after gunshot wounds to the head and neck. Spine 2005;30:2274-9.

18. Gunterberg B, Norlen L, Stener B, et al. Neurologic evaluation after resection of the sacrum. Invest Urol 1975;13:183-8.

19. Gunterberg B, Romanus B, Stener B. Pelvic strength after major amputation of the sacrum: an experimental study. Acta Orthop Scand 1976;47:635-42.

20. Furlow TW. Neurologic manifestations of sacral lesions. In: Doty JR, Rengachary SS, editors. Surgical disorders of the sacrum. New York: Thieme Medical Publishers; 1994. p.34-9.

21. Raque GH Jr, Vitaz TW, Shields CB. Treatment of neoplastic diseases of the sacrum. J Surg Oncol 2001;76:301-7.

22. Heary RF, Vaccaro AR, Mesa JJ, et al. Steroids and gunshot wounds to the spine. Neurosurgery 1997;41:57683.

23. Levy ML, Gans W, Wijesinghe HS, SooHoo WE, Adkins RH, Stillerman CB. Use of methylprednisolone as an adjunct in the management of patients with penetrating spinal cord injury: outcome analysis. Neurosurgery 1996;39:1141-8.

24. Foley KT, Smith MM. Microendoscopic discectomy. Tech Neurosurg 1997;3:301-7.

25. Adamson TE. Microendoscopic posterior cervical laminoforaminotomy for unilateral radiculopathy: results of a new technique in 100 cases. J Neurosurg 2001;95:51-7.

26. Fessler RG, Khoo LT. Minimally invasive cervical microendoscopic foraminotomy: an initial clinical experi- ence. Neurosurgery 2002;51:S37-45.

27. Perez-Cruet MJ, Kim BS, Sandhu F, Samartzis D, Fessler RG. Thoracic microendoscopic discectomy. J Neurosurg Spine 2004;1:58-63.

28. Isaacs RE, Podichetty VK, Santiago P, et al. Minimally invasive microendoscopy-assisted transforaminal lumbar interbody fusion with instrumentation. J Neurosurg Spine 2005;3:98-105.

29. Tredway TL, Santiago P, Hrubes MR, Song JK, Christie SD, Fessler RG. Minimally invasive resection of intradural-extramedullary spinal neoplasms. Neurosurgery 2006;58:ONS52-8.

30. Tredway TL, Musleh W, Christie SD, Khavkin Y, Fessler RG, Curry DJ. A novel minimally invasive technique for spinal cord untethering. Neurosurgery 2007;60:ONS704.

31. Guiot BH, Khoo LT, Fessler RG. A minimally invasive technique for decompression of the lumbar spine. Spine (Phila Pa 1976) 2002;27:432-8.

32. Khoo LT, Beisse R, Potulski M. Thoracoscopic-assisted treatment of thoracic and lumbar fractures: a series of 371 consecutive cases. Neurosurgery 2002;51:S104-17.

33. Huang TJ, Hsu RW, Li YY, Cheng CC. Less systemic cytokine response in patients following microendoscopic versus open lumbar discectomy. J Orthop Res 2005;23:406-11.

34. Park Y, Ha JW. Comparison of one-level posterior lumbar interbody fusion performed with a minimally invasive approach or a traditional open approach. Spine 2007;32:537-43.

35. Wu X, Zhuang S, Mao Z, Chen H. Microendoscopic discectomy for lumbar disc herniation: surgical technique and outcome in 873 consecutive cases. Spine 2006;31:2689-94.

36. Stevens KJ, Spenciner DB, Griffiths KL, et al. Comparison of minimally invasive and conventional open posterolateral lumbar fusion using magnetic resonance imaging and retraction pressure studies. J Spinal Disord Tech 2006;19:77-86.

37. Wang HL, Lu FZ, Jiang JY, Ma X, Xia XL, Wang LX. Minimally invasive lumbar interbody fusion via MAST Quadrant retractor versus open surgery: a prospective randomized clinical trial. Chin Med J (Engl) 2011;124:3868-74. 